\title{
Incidentally discovered pheochromocytoma and aldosterone-producing adenoma in the same adrenal gland
}

\author{
Aurelio Negro, ${ }^{1}$ Rosaria Santi, ${ }^{1}$ Alessandro Giunta, ${ }^{2}$ Filippo Lococo, ${ }^{2}$ Giuseppe Gemelli, ${ }^{3}$ Simonetta Piana, ${ }^{4}$ \\ Moira Ragazzi, ${ }^{4}$ Simonetta Cavalieri ${ }^{5}$ \\ ${ }^{1}$ Internal Medicine and Hypertension Unit; ${ }^{2}$ Oncologic and General Surgery; ${ }^{3}$ Department of Radiology; ${ }^{4}$ Pathology Unit; \\ ${ }^{5}$ Laboratory of Medicine and Endocrinology, Arcispedale Santa Maria Nuova, Reggio Emilia, Italy
}

\begin{abstract}
Simultaneous occurrence of pheochromocytoma and aldosterone-producing adrenocortical tumor has been rarely reported in patients with symptoms or findings suggestive for both neoplasms. Herein, we report and discuss on a challenging case of synchronous pheochromocytoma and aldosterone-producing adenoma incidentally detected in the same adrenal gland and documented by biochemical studies and pathological examination.
\end{abstract}

\section{Introduction}

The simultaneous occurrence of pheochromocytoma and aldosterone-producing adrenal cortical adenoma is extremely rare. ${ }^{1-4}$ In such cases, the diagnostic pathway is often very challenging requiring a strict multidisciplinary cooperation and advanced lab and radiological tests and techniques. We present a case of pheochromocytoma and aldosterone-producing adenoma in the same adrenal gland, which were found in-

Correspondence: Aurelio Negro, Division of Internal Medicine and Hypertension Unit, IRCCS-Arcispedale Santa Maria Nuova, viale Risorgimento 80, 42100 Reggio Emilia, Italy. E-mail: negro.aurelio@asmn.re.it

Key words: Pheochromocytoma; aldosterone-producing adenoma; endocrine neoplasia.

Acknowledgments: the authors would like to thank Dr. Giuseppe Regolisti, Unit of Pathophysiology of Acute and Chronic Renal Failure, University of Parma, for helpful criticism in the final draft of the manuscript.

Contributions: the authors contributed equally.

Conflict of interest: the authors declare no potential conflict of interest.

Received for publication: 31 October 2014.

Revision received: 25 November 2014.

Accepted for publication: 28 November 2014.

This work is licensed under a Creative Commons Attribution NonCommercial 3.0 License (CC BY-NC 3.0).

(C) Copyright A. Negro et al., 2015

Licensee PAGEPress, Italy

Italian Journal of Medicine 2015; 9:294-298

doi:10.4081/itjm.2015.557 cidentally and were documented by biochemical studies and pathological examination.

\section{Case Report}

A 65-year-old female was referred for the evaluation of bilateral adrenal masses, which had been found incidentally at abdominal ultrasonography performed for a clinical suspicion of gallbladder stones, and subsequently studied with magnetic resonance imaging at another institution (imaging unavailable).

She had been diagnosed with grade 2 hypertension at age 40 , and her blood pressure values had become progressively resistant to antihypertensive therapy (ramipril $10 \mathrm{mg} /$ day, amlodipine $10 \mathrm{mg}$ /day and doxazosin $8 \mathrm{mg} /$ day) in the last four years. During this period, routine blood chemistries revealed sporadically only mild hypokalemia ( 3 to $3.5 \mathrm{~m} / \mathrm{Eq} / \mathrm{L}$ ) with normal renal function and blood glucose values. Therefore, spironolactone $50 \mathrm{mg}$ /day was added to her drug therapy by general practitioner, with improvement in the control of her blood pressure values. She had family history of hypertension and coronary artery disease (both parents); neoplasms were not reported in any family members. Her past medical history included intolerance to statins prescribed for familial hypercholesterolemia. In the last five months, the patient had been complaining of epigastric and right flank pain besides mild anxiety and weakness; she denied palpitations, pallor, headache, sweating, tremor, leg cramps or polyuria. At physical examination, blood pressure was $162 / 94 \mathrm{mmHg}$ and the heart rate was $78 \mathrm{bpm}$ and no orthostatic pressure gradient was detected. She was still on treatment with ramipril, amlodipine, doxazosin and spironolactone. Blood cell count was within normal limits. Serum sodium was $143 \mathrm{mEq} / \mathrm{L}$, potassium $3.7 \mathrm{mEq} / \mathrm{L}$, chloride $101 \mathrm{mEq} / \mathrm{L}$ and bicarbonate 27.3 
$\mathrm{mEq} / \mathrm{L}$, glucose $106 \mathrm{mg} / \mathrm{dL}$, creatinine $0.6 \mathrm{mg} / \mathrm{dL}$; urinalysis was unremarkable. Plasma renin activity (PRA) and serum aldosterone were $0.2 \mathrm{ng} / \mathrm{mL} / \mathrm{h}$ and $19 \mathrm{ng} / \mathrm{dL}$ [normal range (n.r.) $0.7-15 \mathrm{ng} / \mathrm{dL}$ ], respectively, with clearly elevated aldosterone/PRA ratio (95 $\mathrm{ng} / \mathrm{dL} / \mathrm{ng} / \mathrm{mL} / \mathrm{h}$ ). Only moderately increased metanephrine and normetanephrine values were detected in 24-h urinary sample [ $521.5 \mathrm{mg} / 24 \mathrm{~h}$ (n.r. 74$297 \mathrm{mg} / 24 \mathrm{~h}$ ) and $788.5 \mathrm{mg} / 24 \mathrm{~h}$ (n.r. $105-354 \mathrm{mg} / 24$ h)], respectively. Morning ( 8 a.m.) plasma cortisol and adrenocorticotropic hormone concentrations were 102 $\mathrm{ng} / \mathrm{mL}$ (n.r. $45-250 \mathrm{ng} / \mathrm{mL}$ ) and $5 \mathrm{pg} / \mathrm{mL}$ (n.r. $5-50$ $\mathrm{pg} / \mathrm{mL}$ ), respectively; while they were $45 \mathrm{ng} / \mathrm{mL}$ (n.r. $15-70 \mathrm{ng} / \mathrm{mL}$ ) and $<5 \mathrm{pg} / \mathrm{mL}$ (n.r. $5-50 \mathrm{pg} / \mathrm{mL}$ ) at 8 p.m., indicating a preserved circadian rhythm of cortisol secretion. Chromogranin A was slightly increased at $210 \mathrm{ng} / \mathrm{mL}$ (n.r. $20-100 \mathrm{ng} / \mathrm{mL}$ ). An abdominal computed tomography (CT) scan was performed for a clinical suspicion of primary aldosteronism, and revealed a 49x36 mm well-defined mass in the right adrenal gland, with low density ( $8 \mathrm{HU}$ ) and no contrast enhancement, suggestive for adenoma; another 20x18 $\mathrm{mm}$ well-defined mass with moderately higher density $(19 \mathrm{HU})$ and contrast enhancement was present in the left adrenal gland (Figure 1A-C). A fluoro-deoxyglucose-positron emission tomography showed an area of very high uptake in the left adrenal gland [standardized uptake value (SUV) 38], whilst SUV was 2 in the right adrenal gland (Figure 1D). Therefore, after changing drug treatment to a combination of a calcium antagonist and an $\alpha$-receptor blocker, bilateral adrenal vein sampling (AVS) was performed for selective aldosterone and cathecolamines determinations. Intraprocedural plasma cortisol measurement was performed to ascertain bilateral selectivity of AVS. ${ }^{5}$ The results revealed that the left adrenal gland was clearly the source of aldosterone and cathecolamines overproduction (Table 1). Consequently, a left sided adrenalectomy was performed under treatment with doxazosin $(18 \mathrm{mg})$ and atenolol $(50 \mathrm{mg})$.

At macroscopic examination, the surgical specimen showed a $2.5 \times 2 \mathrm{~cm}$ reddish-brown tumor adjacent to a $1 \mathrm{~cm}$ yellowish, well defined nodule (Figure 2A). At histology, the reddish-brown tumor was composed by large sheets of highly pleomorphic cells, with bizarre hyperchromatic nuclei and abundant granular and basophilic cytoplasm. Occasional mitotic figures were present but no necrotic areas were seen.
A

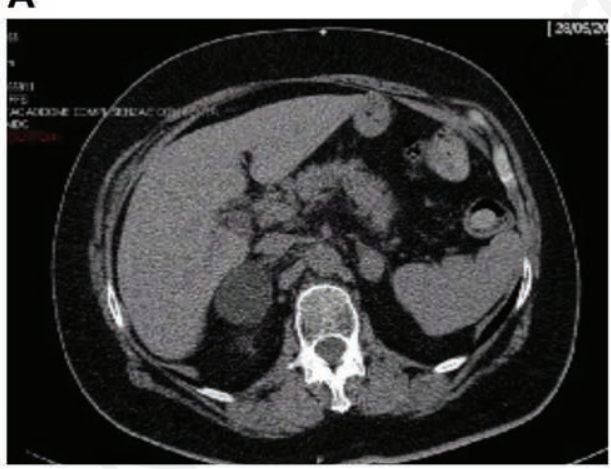

C

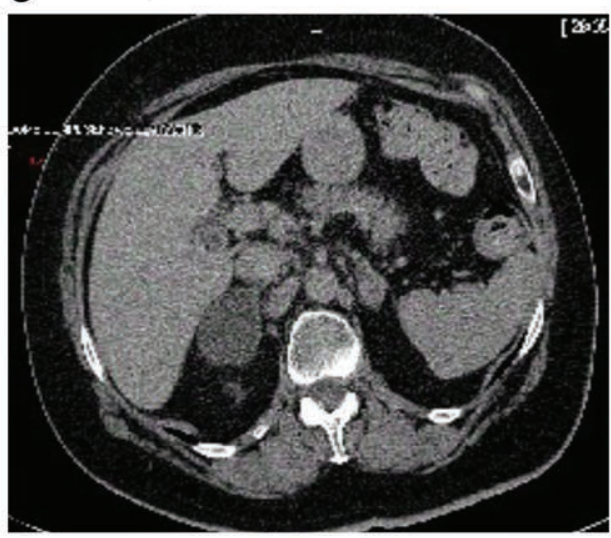

B

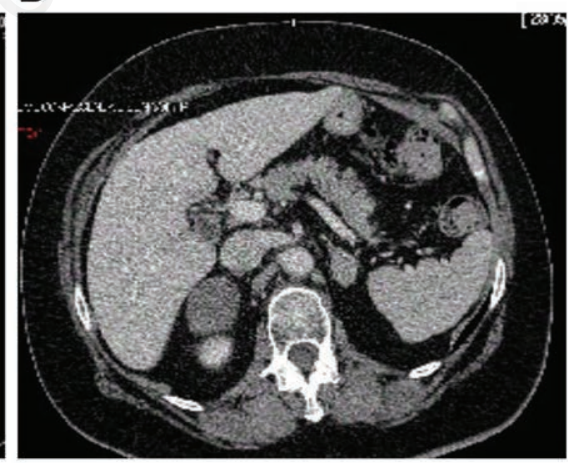

D

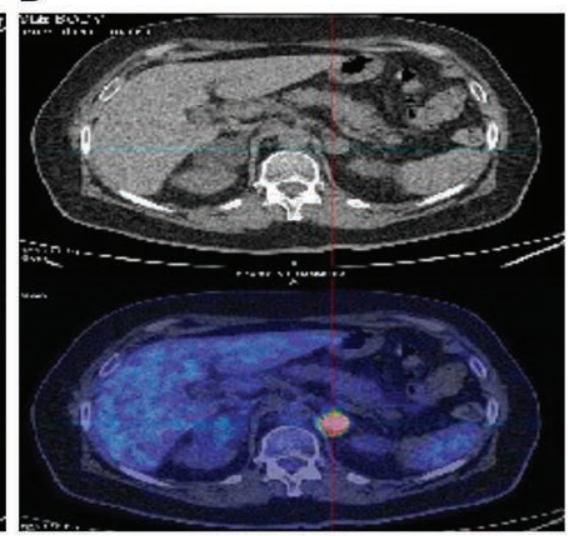

Figure 1. Panels A-C show a large right adrenal mass, with low density, and a smaller left adrenal nodule with higher density and contrast enhancement. Panel D shows very high upatke in the left adrenal gland and fluoro-deoxyglucosepositron emission tomography. 
The tumor was surrounded by a thin capsule that was focally infiltrated with invasion of the surrounding adipose tissue. At immunohistochemistry, the neoplastic cells were immunoreactive with chromogranin and synaptofisin (Figure 2B-E). Based on morphological and immunophenotypic data, a diagnosis of pheocromocytoma (the pheochromocytoma of the adrenal gland scaled score was 9), ${ }^{6}$ was made. The yellowish nodule was made up by monomorphous, bland cell with abundant microvescicular cytoplasm, arranged in

Table 1. Biochemical results of adrenal venous sampling.

\begin{tabular}{lccccc}
\hline & $\begin{array}{c}\text { Cortisol } \\
(\mathbf{n g} / \mathbf{m L})\end{array}$ & $\begin{array}{c}\text { Aldosterone } \\
(\mathbf{p g} / \mathbf{m L})\end{array}$ & $\begin{array}{c}\text { Adrenaline } \\
(\mathbf{p g} / \mathbf{m L})\end{array}$ & $\begin{array}{c}\text { Noradrenaline } \\
(\mathbf{p g} / \mathbf{m L})\end{array}$ & SI* \\
\hline Left adrenal vein & 3300 & 6000 & 4270 & 7938 & 5.70 \\
\hline Right adrenal vein & 16,000 & 3000 & 714 & 1884 & 27.5 \\
\hline IVC & 580 & 250 & 217 & 598 & - \\
\hline
\end{tabular}

SI, selectivity index; IVC, inferior vena cava. * $\mathrm{SI}=$ adrenal vein-to-IVC cortisol ratio. Lateralization index (for aldosterone secretion only) $=10.05$ (cortisol-corrected aldosterone between dominant and nondominant side).

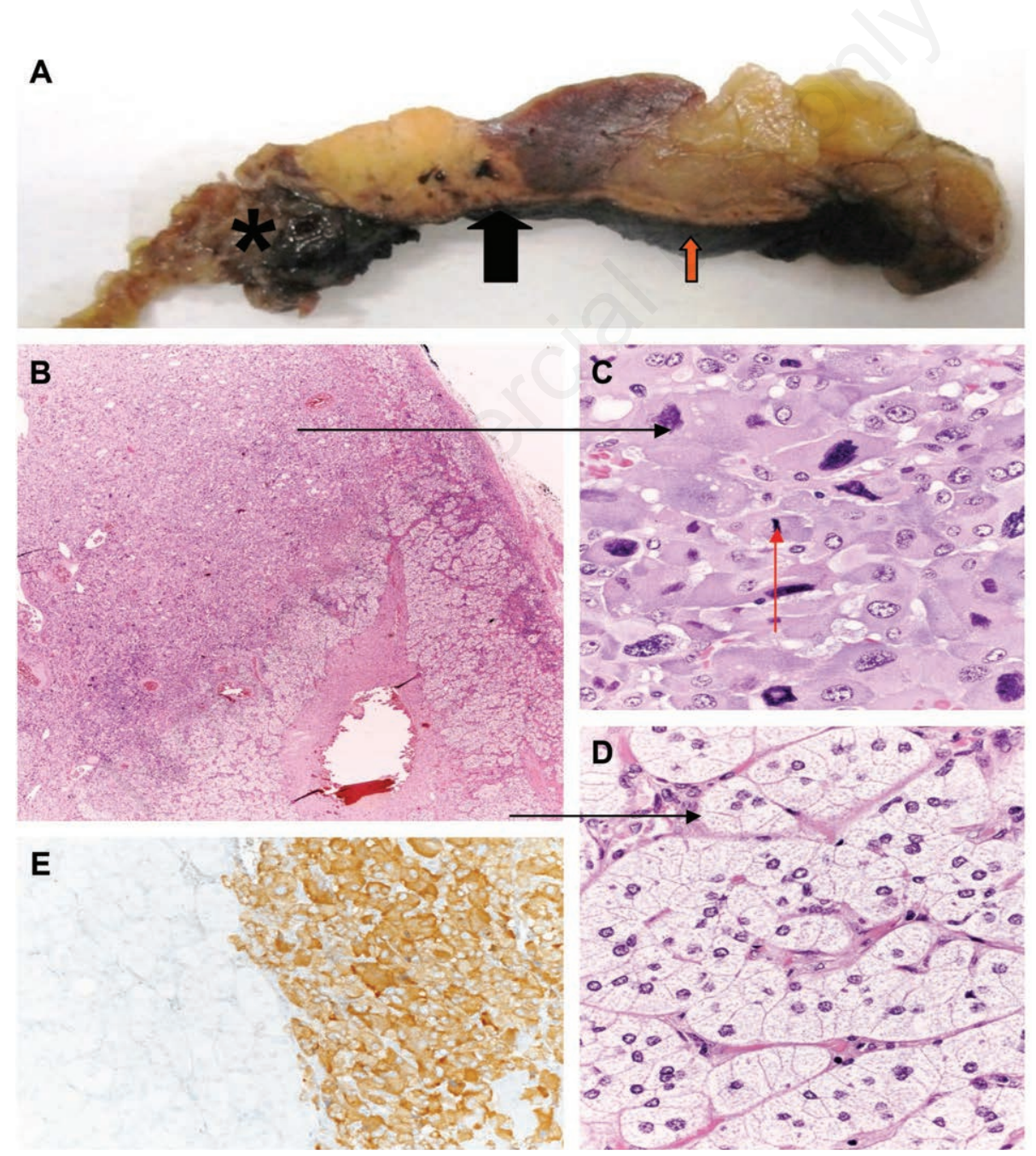

Figure 2. A) Gross section of the surgical sample showing a well-defined yellowish nodule (black arrow) close to a brownish tumor (*). The residual adrenal tissue is evident on the right (red arrow). B) At low power view, the distinction between pheochromocytoma on the left and cortical adenoma on the right is evident, with relatively well-defined margins. C) $\mathrm{A}$ high power view of the pheochromocytoma composed by pleomorphic elements, with bizarre nuclei. A mitotic figure is present in the center of the field (red arrow). D) A high power view of the cortical adenoma, made up by bland polygonal cells, with abundant clear cytoplasm (black arrow). E) The immunohistochemical stain with chromogranin is positive in pheochromocytoma and negative in cortical adenoma. 
discrete nests mimicking the adrenal zona fasciculata. Non mitoses were noted. The lesion was then interpreted as a benign adrenal cortical adenoma adjacent to a pheochromocytoma (Figure 2C).

After surgery, the patient's blood pressure was well controlled (136/82 mmHg) under pharmacological treatment with amlodipine $5 \mathrm{mg} /$ day and ramipril 5 $\mathrm{mg}$ /day. At two months follow-up, PRA and aldosterone values were $1.15 \mathrm{ng} / \mathrm{mL} / \mathrm{h}$ and $9.6 \mathrm{ng} / \mathrm{dL}$, respectively. Complete normalization of 24-h urinary excretion of metanephrine $(112.8 \mathrm{mg} / 24 \mathrm{~h})$ and normetanephrine $(279 \mathrm{mg} / 24 \mathrm{~h})$ was also observed.

\section{Discussion and Conclusions}

The simultaneous occurrence of pheochromocytoma and aldosterone-producing adrenal cortical adenoma is extremely rare. ${ }^{1-4}$ Our case differs substantially from others reported in the literature, in as much as bilateral adrenal mass were detected incidentally on imaging studies, in a patient with very few symptoms or findings typical of secreting pheochromocytoma or hyperaldosteronism. In fact, only transient hypokalemia and gradual development of resistant hypertension oriented us towards an endocrine hypertensive disorder. In this setting, the very low PRA levels strongly pointed to primary aldosteronism; indeed, pheochromocytoma is more frequently characterized by non-suppressible hyper-reninism due to catecholamines-dependent stimulation of $\beta$-adrenergic receptors in juxtaglomerular (JG) apparatus with ensuing JG cells hyperplasia. ${ }^{7-9}$ Ultimately, the complete normalization of PRA, plasma aldosterone and 24-h urinary excretion of metanephrines at follow-up suggests that both neoplasms may have been clinically relevant in maintaining a pattern of resistant hypertension in our patient.

The coexistence of two neoplasms originating from two different regions (i.e., cortex and medulla) in the same adrenal gland may have been due to either a chance or a genetically determined predisposition e.g., multiple endocrine neoplasia. However, the patient's family history was negative for endocrine tumors, and she had no symptoms or findings suggestive for other endocrine disease. Particularly, serum levels of parathyroid hormone and calcitonine were 42 $\mathrm{pg} / \mathrm{mL}$ (n.r. 10-65) and $2 \mathrm{pg} / \mathrm{mL}$ (n.r. 1-6), respectively. Typical signs of neurofibromatosis or von Hippel-Lindau disease were not detected. A genetic testing for the known germline or somatic mutations in the genes associated with pheochromocytoma is yet ongoing. Equally, we are again testing for mutations in KCNJ5 gene, encoding components of the Kir 3.4 potassium channel in the adrenal cortex.

A more intriguing and challenging explanation is that the pheochromocytoma itself may stimulate cell hyperplasia in the contiguous adrenal cortex that could ultimately progress to neoplasia. Among other paracrine and autocrine mediators interacting in the functional regulation of the adrenal glands, urotensin II (UII) is a powerful and widely expressed vasoactive peptide acting through specific UII-receptors (UII-Rs). The finding of UII and UII-Rs in aldosterone-producing adenoma (APA) and pheochromocytoma suggests their participation in the development and growth of neoplasms. ${ }^{10,11}$ In 2009, Giuliani et al. ${ }^{12}$ reported that UII was significantly more expressed in pheochromocytoma than in APA; the opposite was seen for UII-Rs expression pattern, indicating down-regulation of UT-Rs when UII expression is enhanced. A marked increase of plasma aldosterone levels and CYP11B2 enzyme expression in the zona glomerulosa following the infusion of UII in Sprague-Dawley rats was also demonstrated by these investigators. Those effects were stronger than that caused by the infusion of angiotensin II, commonly regarded as the most potent stimulus for aldosterone secretion. Therefore, these Authors hypothesized that UII produced in larger extent in pheochromocytoma cells may stimulate aldosterone secretion modulating the expression of the CYP11B2 gene in the zona glomerulosa of the adrenal cortex.

We cannot establish whether the simultaneous finding of hyperaldosteronism and adrenocortical adenoma in our patient could be attributed to a prolonged stimulation by UII or other substances produced by the pheochromocytoma. Indeed, hyper-reninism may have resulted from circulating cathecolamines stimulating $\beta$ adrenergic receptors in the JC cells, thus increasing serum levels of angiotensin II and finally of aldosterone. However, in our patient secondary aldosteronism was ruled out based on suppressed PRA levels together with an elevated level of plasma aldosterone. We can also speculate that the large mass with low density and no contrast enhancement, detected by the CT scan in the right adrenal gland, may have been expression of the continuum across hyperplasia to neoplasia, possibly induced by prolonged stimulation by a substance produced by the contralateral pheochromocytoma. Moreover, the right adrenal large mass will require a strict follow-up by functional and imaging tests.

In conclusion, during the work-up examination of a patient with suspected pheochromocytoma and history or concomitant hypokalemia a concomitant hyperaldosteronism should be included by the physicians in the differential diagnosis.

\section{References}

1. Hsieh BS, Chen FW, Hsu HC, et al. Hyperaldosteronism with coexistence of adrenal cortical adenoma and pheochromocytoma. J Formos Med Assoc 1979;78: 445-51. 
2. Wajiki M, Ogawa A, Fukui J, et al. Coexistence of aldosteronoma and pheochromocytoma in an adrenal gland. J Surg Oncol 1985;28:75-8.

3. Inoue J, Oishi S, Naomi S, et al. Pheochromocytoma associated with adrenocortical adenoma: Case report and literature review. Endocrinol Jpn 1986;33:67-74.

4. Gordon RD, Bachmann AW, Klemm SA, et al. An association of primary aldosteronism and adrenaline-secreting phaechromocytoma. Clin Exp Pharmacol Physiol 1994;21:219-22.

5. Rossi E, Regolisti G, Negro A, et al. Intraprocedural cortisol measurement increases adrenal vein sampling success rate in primary aldosteronism. Am J Hypertens 2011;24:1280-5

6. Thompson LDR. Pheochromocytoma of the adrenal gland scaled score (PASS) to separate benign from malignant neoplasms. Am J Surg Pathol 2002;26:551-66.

7. Plouin PF, Chatellier G, Rougeot MA, et al. Plasma renin activity in pheochromocytoma: effects of $\beta$-blockade and converting enzyme inhibition. J Hypertens 1988;6:579-85.
8. Kimura N, Sasano N. Hyperplasia or renin-containing cells in a malignant pheochromocytoma: an immunohistochemical and semiquantitative study. Hum Pathol 1986; 17:425-8.

9. Coruzzi P, Musiari L, Biggi A, et al. Renin-angiotensin system unresponsiveness in phaeochromocytoma. J Hum Hypertens 1992;6:239-41.

10. Takahashi K, Totsune K, Murakami O, et al. Expression of urotensin II and its receptor in adrenal tumors and stimulation of proliferation of cultured tumor-cells by urotensin II. Peptides 2003;24:301-6.

11. Zeng ZP, Liu GQ, Li HZ, et al. The effects of urontensin-II on proliferation of pheochromocytoma cells and mRNA expression of urotensin-II and its receptor in pheochromocytoma tissues. Ann NY Acad Sci 2006; 1073:284-9.

12. Giuliani L, Lenzini L, Antonello M, et al. Expression and functional role of urotensin-II and its receptor in the adrenal cortex and medulla: novel insights for the pathophysiology of primary aldosteronism. J Clin Endocrinol Metab 2009;94:684-90. 